\title{
Infant Feeding Websites and Apps: A Systematic Assessment of Quality and Content
}

Sarah Taki ${ }^{1,2}$, MNutDiet; Karen J Campbell ${ }^{2,3}, \mathrm{PhD}$; Catherine G Russell ${ }^{1,2}$, PhD; Rosalind Elliott ${ }^{1,2}$, PhD; Rachel Laws $^{2,3}, \mathrm{PhD}$; Elizabeth Denney-Wilson ${ }^{1,2}, \mathrm{PhD}$

${ }^{1}$ Faculty of Health, University of Technology Sydney, Sydney, Australia

${ }^{2}$ Centre for Obesity Management and Prevention Research Excellence in Primary Health Care (COMPaRE-PHC), Sydney, Australia

${ }^{3}$ Centre for Physical Activity and Nutrition Research, Deakin University, Melbourne, Australia

\section{Corresponding Author:}

Sarah Taki, MNutDiet

Faculty of Health

University of Technology Sydney

Building 10

235 Jones Street

Sydney,

Australia

Phone: 61295142000

Fax: 61295144835

Email: sarah.b.taki@student.uts.edu.au

\section{Abstract}

Background: Internet websites and smartphone apps have become a popular resource to guide parents in their children's feeding and nutrition. Given the diverse range of websites and apps on infant feeding, the quality of information in these resources should be assessed to identify whether consumers have access to credible and reliable information.

Objective: This systematic analysis provides perspectives on the information available about infant feeding on websites and smartphone apps.

Methods: A systematic analysis was conducted to assess the quality, comprehensibility, suitability, and readability of websites and apps on infant feeding using a developed tool. Google and Bing were used to search for websites from Australia, while the App Store for iOS and Google Play for Android were used to search for apps. Specified key words including baby feeding, breast feeding, formula feeding and introducing solids were used to assess websites and apps addressing feeding advice. Criteria for assessing the accuracy of the content were developed using the Australian Infant Feeding Guidelines.

Results: A total of 600 websites and 2884 apps were screened, and 44 websites and 46 apps met the selection criteria and were analyzed. Most of the websites (26/44) and apps (43/46) were noncommercial, some websites (10/44) and 1 app were commercial and there were 8 government websites; 2 apps had university endorsement. The majority of the websites and apps were rated poor quality. There were two websites that had $100 \%$ coverage of information compared to those rated as fair or poor that had low coverage. Two-thirds of the websites (65\%) and almost half of the apps (47\%) had a readability level above the 8th grade level.

Conclusions: The findings of this unique analysis highlight the potential for website and app developers to merge user requirements with evidence-based content to ensure that information on infant feeding is of high quality. There are currently no apps available to consumers that address a variety of infant feeding topics. To keep up with the rapid turnover of the evolving technology, health professionals need to consider developing an app that will provide consumers with a credible and reliable source of information about infant feeding, using quality assessment tools and evidence-based content.

(Interact J Med Res 2015;4(3):e18) doi: 10.2196/ijmr.4323

\section{KEYWORDS}

applications; Internet; infant feeding; health information; quality; suitability; readability 


\section{Introduction}

\section{Background}

The Internet has become a popular medium for consumers seeking health-related information [1]. The proportion of the population regularly accessing the Internet is large and growing: The Australian Bureau of Statistics reports that $83 \%$ of Australians were using the Internet in 2012 and 2013 compared to $76 \%$ in 2010 [2]. In 2014 , the Internet was predominantly accessed via desktop computer $(81 \%)$ compared with $19 \%$ who used mobile phones [3]. However, there was a $33 \%$ increase of people using their mobile phone to access the Internet from 2012 to 2013 [4]. Recent data suggest that searching for health and medical information was one of the top 15 reasons for accessing the Internet among Australians over 14 years of age [5]. In addition to websites, smartphone apps represent another increasingly popular source of health information [6]. A recent US consumer survey identified that one fifth of smartphone owners have downloaded a health app [7]. It is estimated that presently there are more than 100,000 health-related apps available and, with the growth of smartphone ownership, the use of health apps will continue to rise [8].

Increasingly, parents are turning to the Internet for information and support on how and what to feed infants and toddlers in different life stages [9] including infant feeding practices such as breastfeeding, formula feeding, introducing solids, and also the type of foods to introduce [10]. A Google Consumers Survey found that expecting parents conduct Internet searches twice as frequently as nonparents [11]. However, there are concerns regarding the quality of information provided on websites and apps about infant feeding as this may lead to the adoption of inappropriate practices [12].

There is evidence to show that many eating habits and preferences are formed in infancy and childhood and carried through to adulthood [13]. Because poor eating habits such as eating too many energy-dense foods or eating too few fruits and vegetables begin in early life, there is a key opportunity to support parents to get healthy eating established in early life $[14,15]$. Given this, it is important that the information provided to parents is continuously updated and consistent with the latest evidence-based infant and child feeding guidelines, such as the Infant Feeding Guidelines: Information for Health Workers available from the Australian government's National Health and Medical Research Council (NHMRC) [16]. This will ensure that parents have access to sources of information that are credible and of good quality.

Presently, there is little information on the quality of websites and apps accessible in Australia regarding infant feeding practices even though various tools are available for evaluation of the quality of Web-based health information. The evaluation of quality includes assessing the website content, credibility, currency, accuracy, reliability, readability, and design $[17,18]$. However, there is evidence that website developers rarely use these tools [19]. Several studies have evaluated the content of websites and apps focused on health issues such as asthma, pain self-management, and warfarin intake and suggest that the quality of the information and user-friendliness of these resources varied substantially [20-22]. The suitability of health information is also an important aspect to consider; in addition to predicting the appropriateness of the information in terms of content and literacy demands, this also measures graphics and layout and cultural specificity [23]. While health information is widely available on the Web, many individuals with poor health and low literacy may not find the information usable [24]. An overestimation of consumer ability to comprehend the information provided on the Internet may increase the risk of misunderstanding [25].

\section{Objectives}

Given the importance of health-related information targeting infancy and early childhood, conducting an analysis on infant feeding websites and apps is timely. This work will help identify appropriateness and suggest ways in which quality and usability can be improved. This is important if we are to effectively engage consumers around the uptake of healthy infant feeding practices. The aim of this systematic analysis, conducted between December 2013 and December 2014, was to critically evaluate 4 items: quality, comprehensibility, suitability, and readability of information available about infant feeding on websites and apps.

\section{Methods}

\section{Stage 1: Website and App Selection}

\section{Websites}

Infant feeding websites were identified using the Internet Explorer browser and Google and Bing search engines; selection was based on the most commonly used terms in Australia $[26,27]$. The key search terms used for websites included infant feeding, baby feeding, breast feeding, infant feeding schedule, infant formula, formula feeding, introducing solids, introducing baby solids, solids and fussy babies, and introducing solids schedule. These key terms were identified as the most frequently used terms by consumers on Google Trends [28]. A study reports that consumers seldom read beyond the first page of search results for online health information [29]; therefore, the first 30 websites in both of the search engines were screened. The screening of the websites was conducted by researcher LW using predefined inclusion and exclusion criteria. The websites were reviewed if they met the criteria. All websites were cross-checked by researcher ST. Any disagreements regarding which websites should be included in the study were discussed until consensus was reached.

\section{Apps}

Infant feeding apps were identified by performing searches in the digital application distribution platforms for the 2 largest smartphone operating systems: the App Store for iOS (Apple Inc) and Google Play for Android (a Linux-based system currently owned by Google). The search terms were modified slightly for the medium. Revised terms included infant feeding, baby feeding, breast feeding, formula feeding, bottle feeding, baby solids, baby food, and baby weaning. All of the apps yielded from the key terms were screened for eligibility as neither the App Store nor Google Play sorts the most commonly used apps by the number of downloads. The screening of iOS 
apps was conducted by researcher LW, and the screening of Android apps was completed by researcher ST, both using predefined inclusion and exclusion criteria. The apps were reviewed if they met the criteria. All apps were cross-checked by researcher ST. Any disagreements regarding the inclusion of apps in the study were discussed until consensus was reached.

Inclusion criteria for selecting websites and apps for this study included being written in the English language, targeted to parents of infants up to 1 year of age, and last updated after 2002. Websites were also restricted to those which originated from Australia so advice could be compared to the NHMRC's Infant Feeding Guidelines. This requirement did not apply to apps, however, as there are limited methods to restrict country of origin in app stores; to be included they needed to provide at least information on the Australian infant feeding guidelines. The websites and apps must include information on at least one of the following topics around healthy milk feeding behaviors (breast, expressed breast milk, formula feeding, frequency, timing, correct preparation, feeding on demand, nonnutritive feeding, repeated exposure, varied exposure, and reducing exposure to unhealthy food/beverages) or healthy solid food feeding behaviors (age of solid introduction, types of food introduced, repeated exposure, reducing exposure to unhealthy food/beverages). Additionally, websites that could not be accessed due to broken/dead links; apps that were not free; and electronic books, YouTube or other videos, audio files, news, podcasts, blogs, and PDF and Word documents were excluded.

\section{Stage 2: Website and App Evaluation}

\section{Quality Assessment}

\section{Websites}

Two validated tools, the Health-Related Website Evaluation Form (HRWEF) [17] and the Quality Component Scoring System (QCSS) [18,30], were used to assess the quality of websites, as they each contain different criteria.

The HRWEF tool is currently used by the nongovernmental organization Health On the Net Foundation in their code of conduct (HONcode) [31] to certify the quality of an array of health-based websites. It assesses the quality of websites by evaluating the content, credibility, currency, accuracy, reliability, readability, and design of Web-based health information. The QCSS is a tool previously used for medical website evaluations $[30,32]$. The assessment criteria for this tool include purpose of the content; disclosure of authors/sponsors; currency; accuracy and reliability; accessibility and interactivity; readability; and graphics/layout of information [33,34]. The scoring systems of the tools are as follows: in the HRWEF a score of not applicable (0), disagree (1), or agree (2) and in the QCSS no information (0), partial information (1), or complete information (2). A final score assessing each item on both of the tools was calculated. Websites were rated as excellent for scores of $90 \%$ or higher, adequate for $75-89 \%$, or poor for less than $75 \%$ with the HRWEF. With the QCSS tool, they were rated excellent for scores $80 \%$ or higher, very good for $70-79 \%$, good for $60-69 \%$, fair for $50-59 \%$, or poor for less than $50 \%$.

\section{Apps}

To our knowledge there were no published, validated tools available to evaluate the quality of apps. Given this, a quality assessment tool was developed by author ST (see Multimedia Appendix 1). Tools previously developed from other studies $[20,21]$ did not comprehensively address the quality of apps; therefore, the new tool was based on items from the HRWEF tool used for websites [17] and tools used in previous studies $[20,21]$. The criteria used to measure the quality of apps included the description of the app, information about the developer, design and layout, navigation, interactivity, content and accessibility, and security and connectivity of the app. The scoring system used in this tool was attained from one of the studies in which the app quality tool was developed [21]. The scoring system included 29 items which either agreed (1) or disagreed (0) that the app met the criteria and 12 items that were scored as 3 if $100 \%$ of the app met the criteria, 2 if $50-99 \%$ of the app met the criteria, 1 if $1-49 \%$ of the app met the criteria, or 0 if the app did not meet the criteria at all. The final scoring system used was similar to that of the HRWEF tool [17], where a final score rated each app as excellent for a score of $90 \%$ or higher, adequate for $75-89 \%$, or poor for less than $75 \%$ (see Multimedia Appendix 1). The QCSS tool was also used to measure the quality of the apps.

\section{Comprehensiveness}

Comprehensiveness was an item in the quality tools that assessed the accuracy and coverage of the content available on websites and apps. In addition, assessment criteria with 8 topics and 22 subtopics based on the Infant Feeding Guidelines [16] (see Multimedia Appendix 2, with scoring system derived from [35]) were developed to evaluate the consistency of the information provided. For each topic, accuracy was scored as either correct $(+1)$, incorrect $(-1)$, or absent (0) in turn measuring the amount of topics covered in each website and app. Completeness, the breadth of information provided on each topic, was measured as complete (2) or partially complete (1). A final score in the quality assessment tool included 3 if $100 \%$ of information was covered/accurate, 2 if $50 \%$ or more of information was covered/accurate, or 1 if less than $50 \%$ of information was covered/accurate.

\section{Suitability of Information}

The Suitability Assessment of Material (SAM) [23] is a validated instrument, which was used to evaluate the appropriateness of information on the websites and apps for the target audience relating to literacy level, cultural appropriateness, content, and layout. The scoring system used for each item measured included not suitable (0), adequate (1), or superior (2), and each website and app was given a final rating of superior (70-100\%), adequate (40-69\%), or not suitable (0-39\%).

\section{Readability}

The term "readability" refers to the grade level of written text. Readability is an item that was measured with the website and app quality tools and the SAM instrument. Two readability tools were used to measure the content of websites and apps: the Flesch-Kincaid (F-K) [36] and Simple Measure of 
Gobbledygook (SMOG) [37]. Calculations for F-K were automatically performed using a readability statistics feature available on Word Professional version 2010 (Microsoft, Redmond, WA, USA) by pasting a block of writing from each website or app on the Word document and the reading ease and grade level were recorded. The same block of writing was pasted on an online SMOG calculator that automatically calculated the SMOG and F-K reading grade levels. The average level of reading of US and Canadian adults is between 7 th and 8th grade [38,39]. In Australia, literacy competence is measured using the Adult Literacy and Lifeskills Survey, which uses a ranking scale from level 1 (lowest) to level 5 (highest) [40]. As the tools used to measure readability are American, the reading level of information provided could not be compared against the average reading level of Australians. Both the website and app quality assessment tools use a scoring system of agree (2) if the reading level is 8th grade or lower and disagree (1) if the reading level is 9 th grade or higher. For the SAM instrument, the scoring was superior (5th grade or lower), adequate (6th to 8th grade), and not suitable (9th grade or higher).

Figure 1. Flow chart of website and app selection.

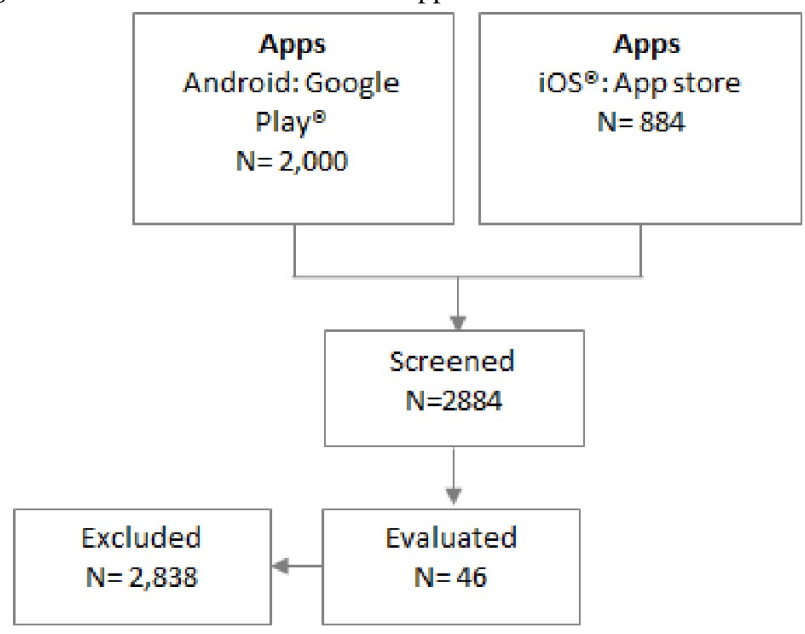

\section{Stage 2: Website and App Evaluation \\ Quality Assessment}

\section{Websites}

Using the HRWEF tool, the majority of the websites (27/44, $61 \%$ ) received a poor rating. The median score was determined to be $65 \%$ and the interquartile range was $55-86 \%$ (Figure 2). Seven of the websites scored an excellent $(>90 \%)$ rating for quality, and 10 websites received scores of adequate. Four websites stated they subscribed to the HONcode principles.

The QCSS tool revealed that $66 \%$ (29/44) of websites were rated poor with a median score of $50 \%$ and interquartile range of $36-76 \%$. Two websites were rated excellent, 2 were very good, 7 were good, 4 were fair, and the majority (29/44) was

\section{Results}

\section{Stage 1: Website and App Selection}

Searches were performed between December 2013 and March 2014 and rerun in December 2014. In total, 600 websites from Google and Bing and 2884 apps from the app stores for were available for screening (Figure 1). After screening and based on the inclusion criteria, 44 websites and 46 apps were evaluated for the quality, comprehensibility, suitability, and readability of the information. Of the 44 websites, 8 were published by government entities, 10 were sponsored by commercial organizations, and 26 were noncommercial sites from education/nonprofit organizations or hospitals. Of the 46 apps, 2 had university and Australian Breastfeeding Association endorsements, 1 was commercial, and 43 were from noncommercial sites. A numbered list of websites and apps included in this study can be found in Multimedia Appendices 4 and 5, and a summary sheet of the scoring criteria for each evaluation tool can be found in Multimedia Appendix 3.

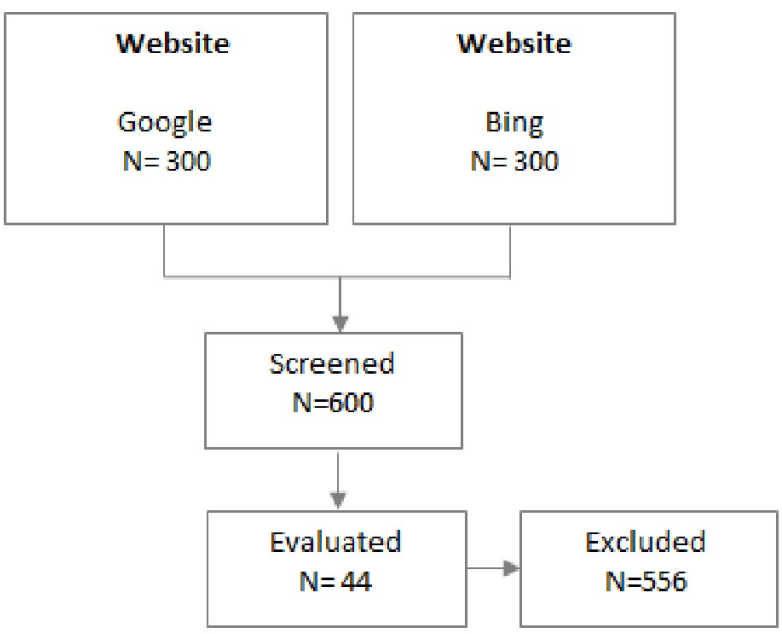

rated poor. Of the 44 websites, 11 reported on author qualifications. Nine of the websites reported that their authors were health care professionals (nutritionists/dieticians, doctors, or nurses/midwives); the authors of 2 websites had no medical expertise (1 was a journalist and 1 was a parent). In regards to the latest content update, 8 websites had not been recently updated to suit the latest infant feeding guidelines (2012) and 7 websites did not identify the date of last update.

Characteristic differences between high- and low-scoring websites varied across the quality items measured. Most websites rated "poor" failed to provide minimal coverage of infant feeding topics, provided inaccurate information, were written at unattainably high reading levels, had not been updated recently, or failed to provide author credentials and external links. 
Figure 2. Quality scores of the websites and apps analyzed in this study.

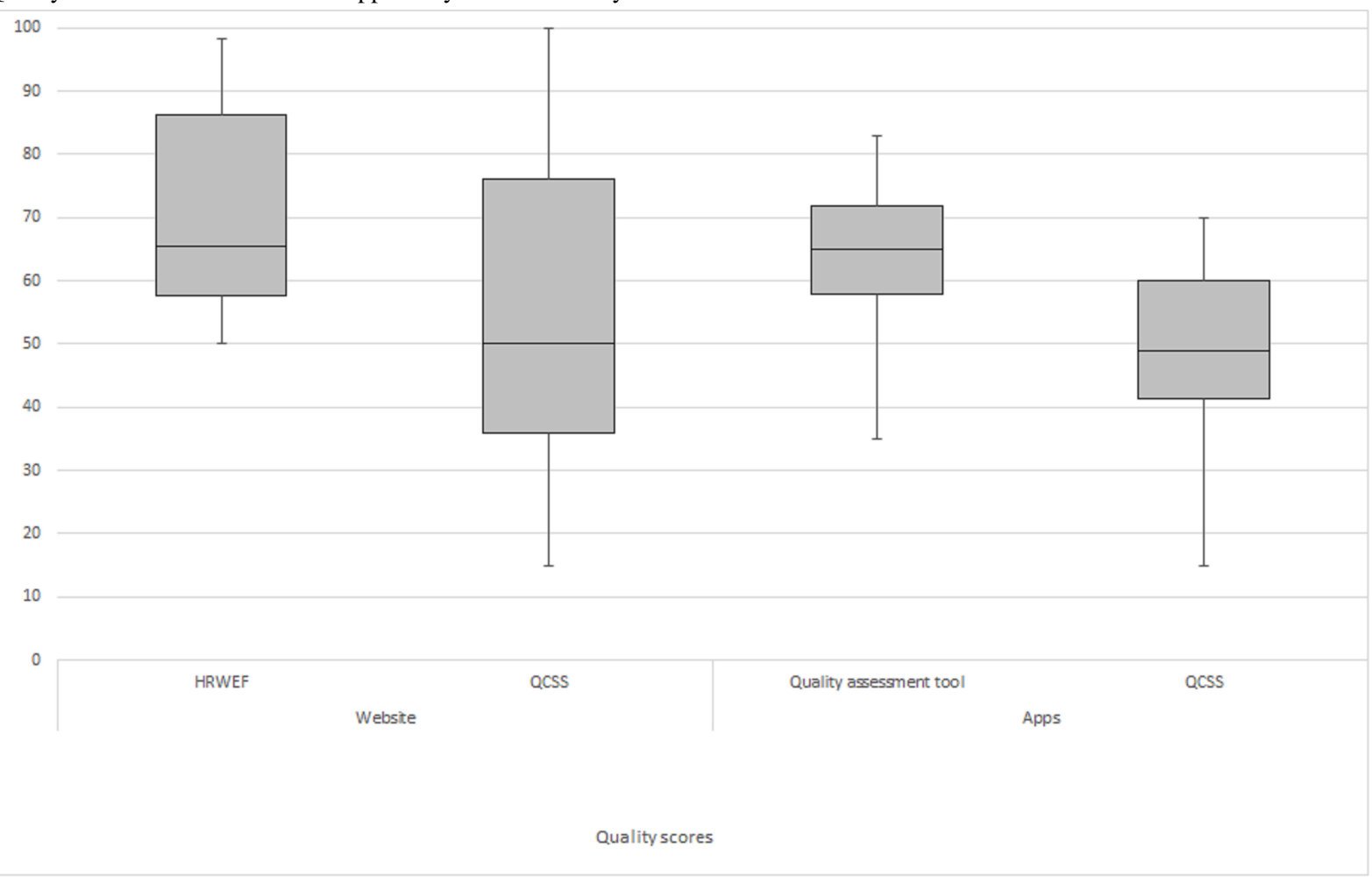

\section{Apps}

Using the quality assessment tool to measure the quality of apps, $78 \%$ (36/46) were rated poor quality, and the median score was $65 \%$ with an interquartile range of $58-71 \%$ (Figure 2). None of the apps scored excellent, and 10 apps scored adequate. Using the QCSS tool, 91\% (42/46) apps were rated poor quality; the median score was $49 \%$ with an interquartile range of $41-60 \%$. Four apps were rated fair and 42 were rated poor. Of the 46 apps, 10 reported author qualifications - 4 were health professionals (nutritionists/dieticians and nurses) and 6 had no medical expertise. The country of origin for the apps was unidentifiable, but only apps written in American, Australian, and British English were selected. Five apps had not been updated to suit the latest guidelines.

Most apps rated poor had deficits in navigability, design, and color; readability; accessibility (text size and help and search options); and breadth of coverage.

\section{Comprehensiveness}

\section{Websites}

Using the Infant Feeding Guidelines to assess the comprehensiveness, there were 2 websites that scored $100 \%$ for comprehensibility, where all 8 topics about infant feeding (see Multimedia Appendix 2) were included and covered, and the information provided was accurate. Two websites had the lowest comprehensibility score $(5 \%)$. Inaccurate information about particular infant feeding practices was identified on 2 websites when compared to the guidelines.

\section{Apps}

Of the 46 apps, the highest score attained for comprehensibility was $78 \%$, and 2 apps scored zero for comprehensibility. Two of the most commonly covered topics in both the websites and apps were Topic 1, encouraging, supporting, and promoting breastfeeding (29/44 and 30/46), and Topic 8, introduction to solids (37/44 and 30/46).

As illustrated in Figure 3, there were very few websites that provided information on all of the subtopics of the infant feeding practices measured in this study. There were no apps that covered the breadth of each topic. Topic 6 , breastfeeding in specific situations, was the least covered, with only $2 \%$ of websites and no apps covering this topic. Overall, websites covered a wider range of infant feeding topics and provided more extensive information about each topic than the apps, but the completeness of each topic is low. 
Figure 3. Topics from the Infant Feeding Guidelines provided on websites and apps in this study.

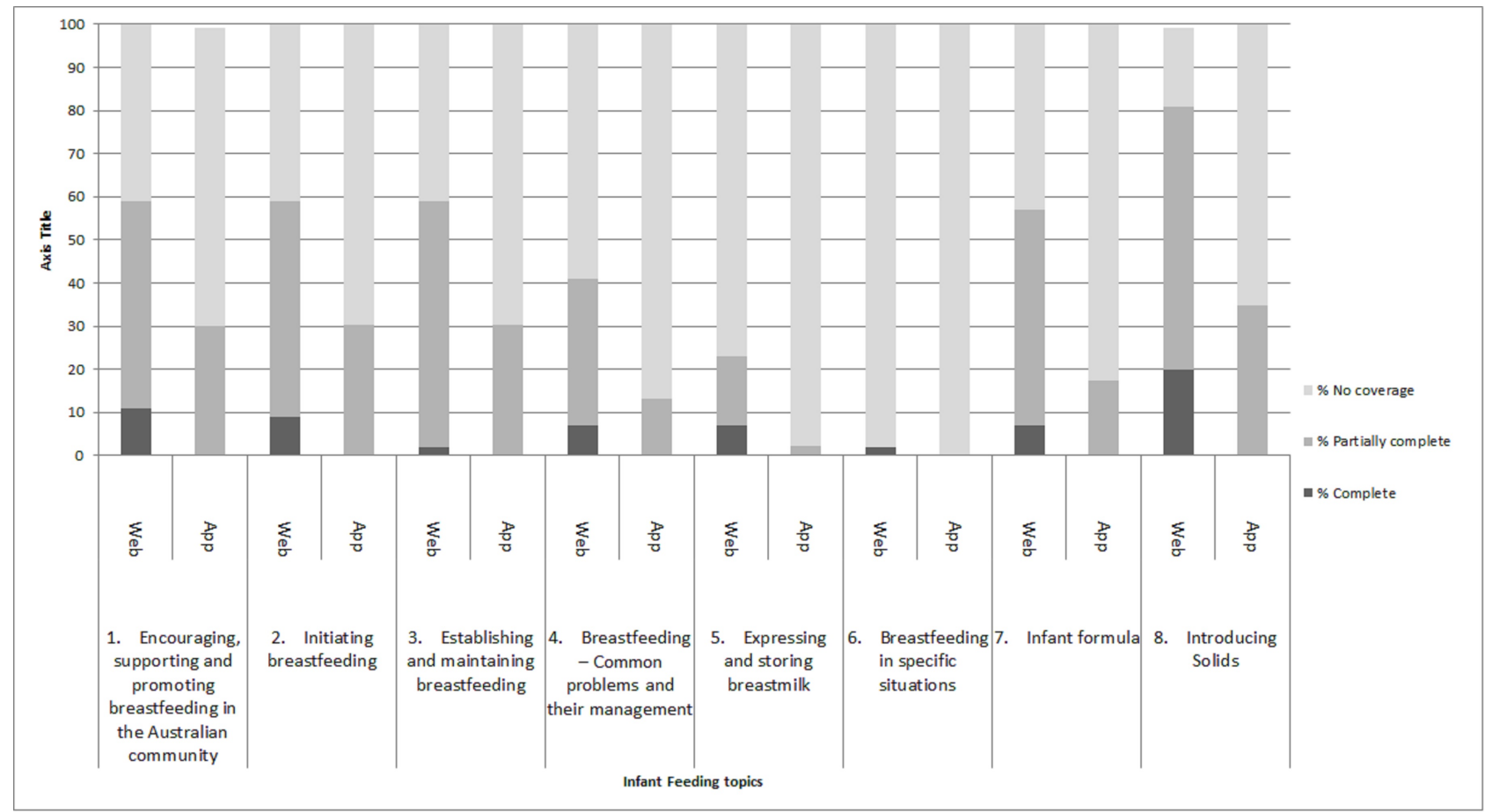

\section{Suitability of Information}

\section{Websites}

Using the SAM tool, 20 websites (45\%) received superior rating for suitability, half attained adequate suitability, and 2 (5\%) were rated poor. In regards to the individual measures of the SAM criteria identified in Table 1, less than half of the websites addressed learning, stimulation, or motivation. None of the websites or apps addressed cultural specificity of information relating to infant feeding practices from diverse backgrounds and demographics.

\section{Apps}

The SAM tool was also used to measure the suitability of the apps. There were 7 apps $(15 \%)$ that achieved superior rating for suitability, 18 apps attained adequate suitability, and 19 (42\%) apps were rated poor. 
Table 1. Infant feeding website and app scores using the SAM criteria.

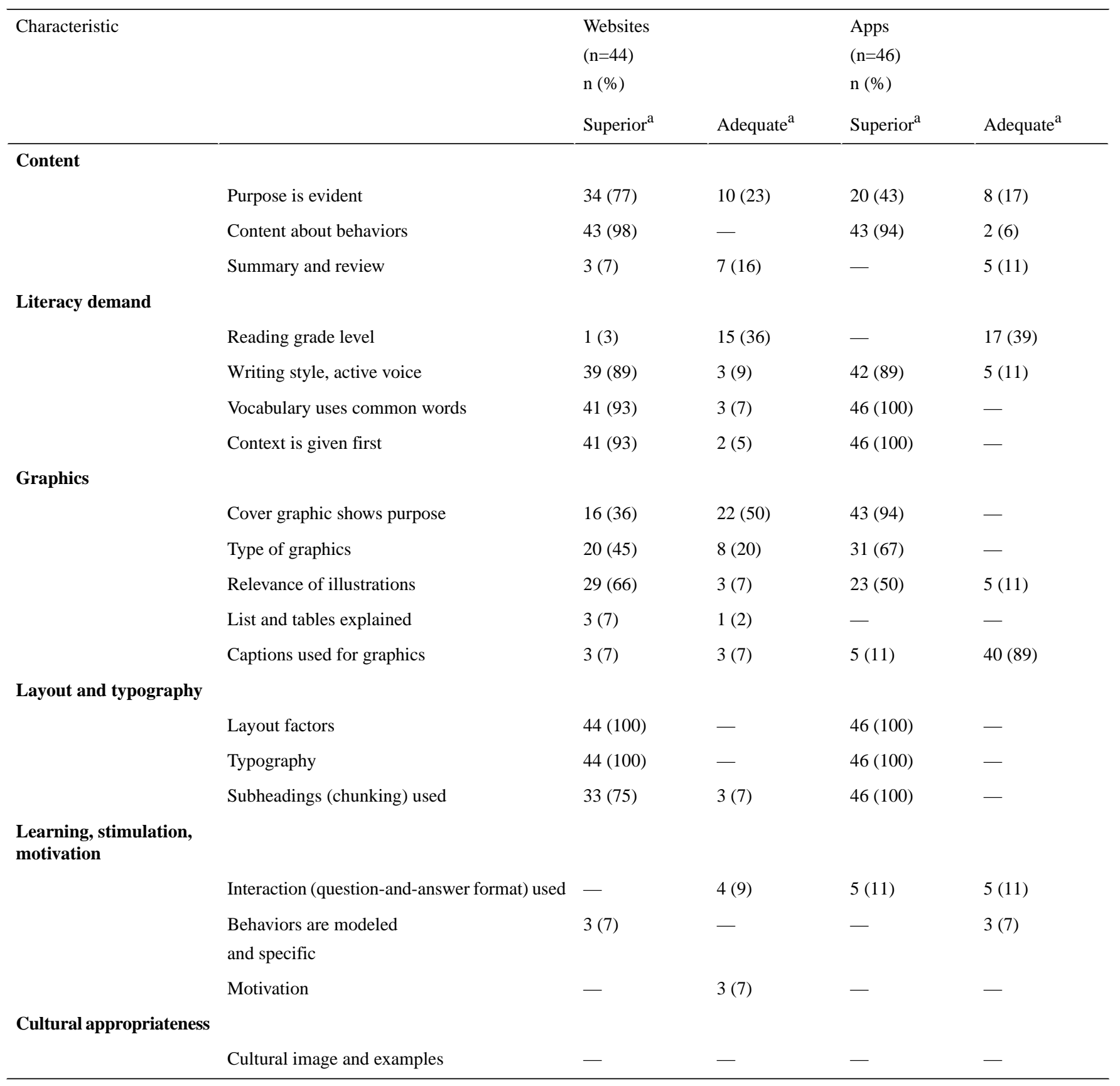

${ }^{\mathrm{a}}$ Required score for adequate suitability is $40-69 \%$; superior, $70-100 \%$.

\section{Readability}

\section{Websites}

Readability grades for all evaluated websites are shown in Table 2 . While there was some variability in the actual readability grades attained, the average was consistent across each of the tools used.

The median readability grade for websites was measured as 9 (interquartile range 8-11) using the F-K test in Word and the online F-K calculator. There were 10 websites that were written at approximately 8th grade level or below, which meets the recommended level of written health information.
The median SMOG readability grade level was measured as 10 (interquartile range 7-10). Using the SMOG formula, 16 of the websites were written at approximately 8th grade level or below.

\section{Apps}

As presented in Table 2, the median readability grade level was 8 (interquartile range 7-10) for apps using the F-K test in Word and the online F-K calculator. There were 14 apps that were written at approximately 8th grade level or below which meets the recommended level of written health information. The median SMOG readability grade levels for apps were measured as 7 (interquartile range 7-8). Using the SMOG formula, 20 of the apps were written at approximately 8 th grade level or below. 
Table 2. Readability scores.

\begin{tabular}{|c|c|c|c|c|}
\hline & & F-K grade $^{a}$ & F-K grade $^{b}$ & SMOG grade \\
\hline \multicolumn{5}{|c|}{ Websites } \\
\hline & Median & 9 & 9 & 10 \\
\hline & Interquartile range & $8-11$ & $8-11$ & $7-10$ \\
\hline \multicolumn{5}{|c|}{ Apps } \\
\hline & Median & 8 & 8 & 7 \\
\hline & Interquartile range & $7-10$ & $7-10$ & $7-8$ \\
\hline
\end{tabular}

${ }^{a}$ Flesch-Kincaid test: Word

${ }^{\mathrm{b}}$ Flesch-Kincaid test online

\section{Discussion}

\section{Principal Findings}

To our knowledge, this is the first systematic analysis to evaluate websites and smartphone apps providing information on infant feeding practices. This analysis examined the quality standards of information on infant feeding available to users. It also ascertained that there is a need for the development of reliable websites or apps about infant feeding practices that are accessible to health professionals and the general public.

This systematic analysis found that the majority of the websites and apps on infant feeding had poor quality ratings. In contrast, other studies which have evaluated health-related information from websites using similar tools reported adequate ratings for the majority of included websites [22,32]. Another study analyzing apps for the management of obesity using a developed tool rated the majority of apps as fair [41]. One reason resources regarding obesity treatment and infant feeding may be of poorer quality is that a broader group of interested parties, such as journalists and parents, may be involved in website/app development. This would contrast with medical conditions where we might expect expert input and consequent improvement in quality. In turn, this may impact a number of assessed items including credibility of the source, accuracy and coverage of the information, and use of references. Low quality scores were influenced by the number of authors lacking medical backgrounds developing these resources and also the lack of information about author credibility (missing in $75 \%$ of the websites and $78 \%$ of the apps). Website credibility is one way in which consumers can make a judgment about the quality of information posted on sites [42]. Without this information, consumers may access low quality sites with misleading and inaccurate information.

Commercial websites scored the lowest quality rating, a finding consistent with other studies $[34,43]$. This finding supports the proposition that commercially motivated sites may set different criteria for information provision and may not represent the existing evidence-based practices [34]. It is of interest that a British qualitative study analyzing maternal accounts of trust regarding healthy eating information sources reported that food manufacturers were the least trusted source for Web-based health information [44]. Regardless, to minimize the risk of consumers accessing websites that may have misleading or

inaccurate information, we propose that website developers should use a tool such as HONcode in the early stages of development. Currently in Australia, only medical apps which are used as diagnostic or monitoring tools require approval from the Therapeutic Goods Administration. General health and well-being apps are not regulated [45]. We propose that health apps should also be examined for approval before becoming available to consumers.

\section{Certifying Health Websites and Apps}

Of note, 4 websites stated they subscribed to HONcode principles. Of these, 2 websites attained excellent quality scores. Therefore, using a tool such as HONcode provides a certified endorsement to indicate good quality and encourages website developers to maintain the quality standards of the organization. A qualitative study found that online health information seekers do not commonly evaluate the credibility of sources [46]. Participants lacked the skill to assess website credibility as there was no report of using the About Us section, disclaimer, or disclosure on the websites. The participants' perceived method to assess credibility was to eyeball the available source, design, and layout of the website, language used, ease of navigation. Given this, using a certified endorsement on websites has the potential to reduce the burden for consumers to search for good quality websites and apps [47].

Another benefit of using a certified endorsement organization to regulate the quality of websites and apps is to ensure that the information shared is constantly updated and in line with appropriate guidelines; more recently updated websites and apps scored higher in quality than those with earlier dates of revision. These findings are similar to a study that assessed smartphone apps around pharmacology education and reported that apps included in their study had not been updated for several years, and the reliability and accuracy of the content were questioned [48]. However, with the rapid growth of apps and constant update of app versions, there is a need to continuously assess and regulate these sources [48]. A study that examined the evolution of asthma-based apps found that the number of apps on asthma more than doubled over 2 years [49]. Although the study's findings reported no difference in the comprehensiveness of the information available in the newer apps, they did identify improvements in the features offered. Therefore, later versions of apps scored better due to the ease of navigation, updated content, and appropriate layout and graphics. Furthermore, using a certified endorsement may be a 
useful strategy for policy makers to regulate the information on health websites and apps before allowing it to become available to the public. Another policy innovation might include action by the NHMRC to provide an app with the release of every new Infant Feeding Guidelines, which could be made available to parents and health practitioners. This innovation would be potentially powerful as the people responsible for reviewing the evidence could contribute directly to the dissemination strategy (the app) thus reducing any problems in translating evidence into practice.

Another factor contributing to the poor quality of the websites and apps was the level of comprehensibility, including coverage of topics and the completeness of the information on each topic about infant feeding. Our study found that most websites did not cover a range of topics nor did they provide in-depth information about each topic. Similar findings were identified in a study that analyzed online information about dementia, where very few websites covered all topics [50]. Despite the efficiency that has been associated with using the Internet to find health information, websites that lack in information and do not cover a range of topics become a limitation and are no longer a reliable source [51]. Consumers then need to access various websites or apps to obtain information about a particular health subject. Therefore, website and app designers who do not include a range of topics around health information should consider including references that thoroughly cover topics not discussed [50]. In addition to using appropriate specific guidelines and tools to develop good quality websites and apps, they should consider assessing user requirements specific to health conditions and topics in order to meet user needs and expectations [52].

\section{Adherence to Health Information Best Practice Principles}

From the analysis of this study, 3 websites addressed the widest range of topics and attained high completeness scores, as they provided an appropriate level of detail consistent with the Australian Infant Feeding Guidelines. Only 4 websites provided incorrect information. These findings are consistent with other studies which have reported on the comprehensiveness of information related to guidelines [20,42]. Incorrect information provided in resources may have serious implications, as the layperson may not be familiar with the Infant Feeding Guidelines and might be misguided in the practice of infant feeding.

This study highlights that most of the websites and apps were written at a reading level of 12 th grade. This analysis is consistent with other studies [22,53] and is an important finding given that, as previously noted, the average reading level has been reported to be between 7 th and 8th grade $[38,39]$. It is crucial that app and website developers consider literacy levels of the general population as health-related information may be challenging for users with low literacy skills (poorly educated, culturally diverse background) [54]. It is particularly important given those with the least education and lower reading levels may benefit most from well-targeted information, advice, and support.
In our evaluation of the suitability of infant feeding information, we rated the majority of the websites superior or adequate, whereas most of the apps were rated as poor. Using the SAM criteria, poor graphics and low levels of cultural appropriateness were notably deficient. This finding supports a study [53] that reported from a review of Web-based information on osteoporosis that few websites were culturally appropriate. Australia is ethnically diverse, and Internet access is high across all social groups. Given this, culturally appropriate information should be presented across websites and apps [55]. A study evaluating health information on websites about cancer therapy [56] illustrated the difficulty of presenting information to all ethnic backgrounds. As infant feeding practices can vary with different cultural backgrounds (eg, diets, religious beliefs), it is important for website and app developers to consider identifying these aspects in the early stages of development.

\section{Limitations and Strengths}

There are a number of potential limitations of this study that need to be considered. First, the study was limited to evaluating websites and apps written in the English language and websites targeting the Australian population. Therefore, the findings may not be representative of websites and apps written in other languages or from other countries. Another limitation on this point is the fact that this study included only Australian websites while the apps were accepted regardless of the country of origin. Given this, it may have influenced the findings about the comprehensibility and accuracy of the content. There is a potential that the websites may have attained higher comprehensibility scores compared to apps, as the websites would most likely include information from the Australian guidelines compared to the apps. Another limiting factor which may have impacted quality scores of apps is that app development is in its infancy compared to website development. The fact that there is not yet a published quality tool to measure apps enforces the point that there is still much research that needs to be undertaken around health-related apps. Furthermore, Internet and smartphone apps are continuously updated, limiting the likelihood of receiving similar findings using the search terms from this study if it were replicated. To minimize this limitation, the author used Google Trends to identify commonly searched terms around infant feeding practices. Another limitation identified is that the subjective nature of some quality and suitability criteria may impact variability in scoring. Two researchers conducted searches for websites and apps and measured quality and suitability, but only one of the researchers cross-checked the websites and apps. An important strength of this study was the use of 2 different tools to measure the quality and readability of the websites and apps, a method which in turn enabled a comparison of the results.

\section{Conclusion}

It is evident that there are key areas for improvement to increase the utility of information related to infant feeding practices on websites and apps. A majority of websites and apps were of poor quality and had inappropriately high reading levels; few were given a good rating. There were no apps in this study which addressed all of the topics from the Australian Infant Feeding Guidelines. Government implementation of policy or 
certification systems such as HONcode would enable consumers to identify reliable and appropriate information. It would also would ensure that the readability level is appropriate for vulnerable populations. Involving users early in the development of health apps is advised as establishing ways to merge user requirements with evidence-based content to provide high-quality apps.

\section{Acknowledgments}

The research reported in this paper is a project of the Australian Primary Health Care Research Institute, which is supported by a grant from the Australian government Department of Health and Ageing. The information and opinions contained in it do not necessarily reflect the views or policies of the Australian Primary Health Care Research Institute or the Australian government Department of Health and Ageing. The authors would like to acknowledge the input of Louisa Wilson who assisted with the screening process and analysis of the websites and apps included in this study.

\section{Conflicts of Interest}

None declared.

\section{Multimedia Appendix 1}

Quality criteria assessment for smartphone apps.

[PDF File (Adobe PDF File), 355KB-Multimedia Appendix 1]

\section{Multimedia Appendix 2}

Information guide sheet for content (accuracy and coverage).

[PDF File (Adobe PDF File), 269KB-Multimedia Appendix 2]

\section{Multimedia Appendix 3}

Summary sheet of the scoring criteria for evaluation tools and items measured.

[PDF File (Adobe PDF File), 346KB-Multimedia Appendix 3]

\section{Multimedia Appendix 4}

List of websites included in this systematic analysis.

[PDF File (Adobe PDF File), 201KB-Multimedia Appendix 4]

\section{Multimedia Appendix 5}

List of apps included in this systematic analysis.

[PDF File (Adobe PDF File), 200KB-Multimedia Appendix 5]

\section{References}

1. Eysenbach G, Powell J, Kuss O, Sa E. Empirical studies assessing the quality of health information for consumers on the world wide web: a systematic review. JAMA 2002;287(20):2691-2700. [Medline: 12020305]

2. Household Use of Information Technology, 2012-13.: Australian Bureau of Statistics URL: http://www.abs.gov.au/ausstats/ abs@.nsf/Lookup/8146.0Chapter12012-13 [accessed 2015-01-20] [WebCite Cache ID 6ViQuevs3]

3. Digital marketing report, 2014: Australian Internet and social media. Queensland, Australia: Margin Media URL: http:/ /blog.marginmedia.com.au/Our-Blog/bid/99581/Australian-Internet-and-Social-Media-Statistics-January-2014[WebCite Cache ID 6Vi7y6142]

4. Australia's mobile digital economy: ACMA confirms usage, choice, mobility and intensity on the rise.: Australian Communications and Media Authority URL: http://www.acma.gov.au/theACMA/Library/Corporate-library/ Corporate-publications/australia-mobile-digital-economy [accessed 2015-02-06] [WebCite Cache ID 6W8SR8AvG]

5. Consumer benefits from participating in the digital economy. URL: http://www.acma.gov.au/webwr/ assets/main/lib410148/ chapter\%205 consumer benefits from participating in the digital economy.pdf [accessed 2015-01-20] [WebCite Cache ID 6ViH4cfTb]

6. West J, Hall PC, Hanson CL, Barnes MD, Giraud-Carrier C, Barrett J. There's an app for that: content analysis of paid health and fitness apps. J Med Internet Res 2012;14(3):e72 [FREE Full text] [doi: 10.2196/jmir.1977] [Medline: 22584372] 
7. Fox S, Duggan M. Internet, Science \& Tech: Mobile health 2012.: Pew Research Center; 2012. URL: http://www. pewinternet.org/2012/11/08/mobile-health-2012/ [accessed 2015-08-24] [WebCite Cache ID 6b0tzb3IF]

8. Aitken M, Gauntlett C. Patient Apps for Improved Healthcare.: IMS Institute for Healthcare Informatics; 2013. URL: http:/ /www.imshealth.com/deployedfiles/imshealth/Global/Content/Corporate/IMS\%20Health\%20Institute/Reports/Patient_Apps/ IIHI Patient Apps Report.pdf [accessed 2015-08-25] [WebCite Cache ID 6b1MgjZx8]

9. Buultjens M, Robinson P, Milgrom J. Online resources for new mothers: opportunities and challenges for perinatal health professionals. J Perinat Educ 2012;21(2):99-111 [FREE Full text] [doi: 10.1891/1058-1243.21.2.99] [Medline: 23449623]

10. Bernhardt J, Felter EM. Online pediatric information seeking among mothers of young children: results from a qualitative study using focus groups. J Med Internet Res 2004 Mar 1;6(1):e7 [FREE Full text] [doi: 10.2196/jmir.6.1.e7] [Medline: 15111273]

11. Rost J, Johnsmeyer B, Mooney A. Diapers to diplomas: what's on the minds of new parents. URL: http://wwhttps://www. thinkwithgoogle.com/articles/new-parents.htmlw.imshealth.com/deployedfiles/imshealth/Global/Content/Corporate/ IMS\%20Health\%20Institute/Reports/Patient_Apps/IIHI_Patient_Apps_Report.pdf [accessed 2015-08-25] [WebCite Cache ID $6 \mathrm{~b} 1 \mathrm{MrRkBS}]$

12. Rosser BA, Eccleston C. Smartphone applications for pain management. J Telemed Telecare 2011;17(6):308-312. [doi: 10.1258/jtt.2011.101102] [Medline: 21844177]

13. Skinner JD, Carruth BR, Bounds W, Ziegler P, Reidy K. Do food-related experiences in the first 2 years of life predict dietary variety in school-aged children? J Nutr Educ Behav 2002;34(6):310-315. [Medline: 12556269]

14. Starling WP, Reifsnider E, Domingeaux EM. Changes in family variables among normal and overweight preschoolers. Issues Compr Pediatr Nurs 2010;33(1):20-38. [doi: 10.3109/01460860903486531] [Medline: 20121578]

15. Spence AC, McNaughton SA, Lioret S, Hesketh KD, Crawford DA, Campbell KJ. A health promotion intervention can affect diet quality in early childhood. J Nutr 2013 Oct;143(10):1672-1678 [FREE Full text] [doi: 10.3945/jn.113.177931] [Medline: 23966329]

16. Infant feeding guidelines: information for health workers. Australia: National Health and Medical Research Council, Department of Health and Ageing; 2012. URL: https://www.nhmrc.gov.au/_files_nhmrc/publications/attachments/ n56 infant feeding guidelines.pdf [accessed 2015-08-25] [WebCite Cache ID 6b1N2JHtw]

17. Pealer LN, Dorman SM. Evaluating health-related Web sites. J Sch Health 1997 Aug;67(6):232-235. [Medline: 9285869]

18. Ghezzi P, Chumber S, Brabazon T. Educating Medical Students to Evaluate the Quality of Health Information on the Web. In: Floridi L, Illari P, editors. Chumber, and T. Brabazon, Educating Medical Students to Evaluate the Quality of Health Information on the Web, in The Philosophy of Information Quality, Springer. Switzerland: Springer International Publishing; 2014:183-199.

19. Reichow B, Shefcyk A, Bruder MB. Quality comparison of websites related to developmental disabilities. Res Dev Disabil 2013 Oct;34(10):3077-3083. [doi: 10.1016/j.ridd.2013.06.013] [Medline: 23891722]

20. Huckvale K, Car M, Morrison C, Car J. Apps for asthma self-management: a systematic assessment of content and tools. BMC Med 2012;10:144 [FREE Full text] [doi: 10.1186/1741-7015-10-144] [Medline: 23171675]

21. Reynoldson C. Assessing the Quality and Usability of Smartphone Apps for Pain Self-Management. Pain Medicine: p. n/a-n/a 2014. [doi: 10.1111/pme.12327]

22. Nasser S, Mullan J, Bajorek B. Assessing the quality, suitability and readability of internet-based health information about warfarin for patients. Australas Med J 2012;5(3):194-203 [FREE Full text] [doi: 10.4066/AMJ.2012862] [Medline: 22952566]

23. Doak CC, Doak LG, Root JH. Teaching patients with low literacy skills. Amer J Nursing 1996;96(12):16. [Medline: 049277]

24. Birru M, Monaco VM, Charles L, Drew H, Njie V, Bierria T, et al. Internet usage by low-literacy adults seeking health information: an observational analysis. J Med Internet Res 2004 Sep 3;6(3):e25 [FREE Full text] [doi: 10.2196/jmir.6.3.e25] [Medline: 15471751$]$

25. Walsh TM, Volsko TA. Readability assessment of internet-based consumer health information. Respir Care 2008 Oct;53(10):1310-1315 [FREE Full text] [Medline: 18811992]

26. Murton D. Australian Internet and Social Media.: Margin Media URL: http://blog.marginmedia.com.au/our-blog/ australian-internet-and-social-media-statistics-february-2015 [accessed 2015-08-25] [WebCite Cache ID 6b1OEBNq3]

27. Top 5 Desktop, Tablet and Console Search Engines in Australia from Oct 2012 to Oct 2013.: StatCounter; 2015. URL: http://gs.statcounter.com/\#browser-ww-monthly-201210-201310 [accessed 2015-09-16] [WebCite Cache ID 6Vjrw2fN9]

28. Google. Google Trends 2015 URL: https://www.google.com/trends/explore\#q=baby\%20feeding [accessed 2015-02-02] [WebCite Cache ID 6W2iGxaDm]

29. Morahan-Martin JM. How internet users find, evaluate, and use online health information: a cross-cultural review. Cyberpsychol Behav 2004 Oct;7(5):497-510. [Medline: 15667044]

30. Martins EN, Morse LS. Evaluation of internet websites about retinopathy of prematurity patient education. Br J Ophthalmol 2005 May;89(5):565-568 [FREE Full text] [doi: 10.1136/bjo.2004.055111] [Medline: 15834086]

31. Health on the Net Foundation: HONcode. URL: http://www.hon.ch/HONcode/Patients/method.html [accessed 2015-02-06] [WebCite Cache ID 6W8R3eP71]

32. Peterlin BL, Gambini-Suarez E, Lidicker J, Levin M. An analysis of cluster headache information provided on internet websites. Headache 2008 Mar;48(3):378-384. [doi: 10.1111/j.1526-4610.2007.00951.x] [Medline: $\underline{18005143]}$ 
33. Harland J, Bath P. Assessing the quality of websites providing information on multiple sclerosis: evaluating tools and comparing sites. Health Informatics J 2007 Sep;13(3):207-221. [doi: 10.1177/1460458207079837] [Medline: 17711882]

34. van der Marel Sander, Duijvestein M, Hardwick JC, van den Brink Gijs R, Veenendaal R, Hommes DW, et al. Quality of web-based information on inflammatory bowel diseases. Inflamm Bowel Dis 2009 Dec;15(12):1891-1896. [doi: 10.1002/ibd.20976] [Medline: 19462423 ]

35. Pandolfini C, Impicciatore P, Bonati M. Parents on the web: risks for quality management of cough in children. Pediatrics 2000 Jan;105(1):e1. [Medline: 10617738]

36. Si L, Callan J. A statistical model for scientific readability. In: Statistical Model for Scientific Readability in Proceedings of the tenth international conference on Informationknowledge management. . ACM. 2001 Oct 05 Presented at: Conference on Information and Knowledge Management; 2001; New York. [doi: 10.1145/502585.502695]

37. McLaughlin G. H., Smog Grading: A New Readability Formula. Journal of reading 1969;12(8):639-646.

38. National Assessment of Adult Literacy 2003. o URL: http://nces.ed.gov/naal/ [accessed 2015-02-06] [WebCite Cache ID 6W8SEn1V4]

39. Adult Literacy and Lifeskills Survey.: National Center for Educational Statistics, US Department of Education URL: https:/ /nces.ed.gov/surveys/all/ [accessed 2015-08-25] [WebCite Cache ID 6b1OzRbfl]

40. Australian Social Trends, 2008: Adult Literacy.: Australian Bureau of Statistics URL: http://www.abs.gov.au/AUSSTATS/ abs@.nsf/Lookup/4102.0Chapter6102008 [accessed 2015-02-02] [WebCite Cache ID 6W2neVPWl]

41. Gan KO, Allman-Farinelli M. A scientific audit of smartphone applications for the management of obesity. Aust N Z J Public Health 2011 Jun;35(3):293-294. [doi: 10.1111/j.1753-6405.2011.00707.x] [Medline: 21627732]

42. Rains S, Karmikel C. Health information-seeking and perceptions of website credibility: Examining Web-use orientation, message characteristics, and structural features of websites. Computers in Human Behavior 2009 Mar;25(2):544-553. [doi: 10.1016/j.chb.2008.11.005]

43. Thakurdesai PA, Kole PL, Pareek RP. Evaluation of the quality and contents of diabetes mellitus patient education on Internet. Patient Educ Couns 2004 Jun;53(3):309-313. [doi: 10.1016/j.pec.2003.04.001] [Medline: 15186868]

44. O'Key V, Hugh-Jones S. I don't need anybody to tell me what I should be doing'. A discursive analysis of maternal accounts of (mis)trust of healthy eating information. Appetite 2010 Jun;54(3):524-532. [doi: 10.1016/j.appet.2010.02.007] [Medline: 20170695]

45. Sutton M, Fraser M. The Rise of Smartphone Health and Medical Apps. 2013. URL: http://lifescientist.com.au/content/ biotechnology/article/the-rise-of-smartphone-health-and-medical-apps-1072193834 [accessed 2015-01-26] [WebCite Cache ID 6Vs4ALQDQ]

46. Eysenbach G, Köhler C. How do consumers search for and appraise health information on the world wide web? Qualitative study using focus groups, usability tests, and in-depth interviews. BMJ 2002 Mar 9;324(7337):573-577 [FREE Full text] [Medline: 11884321$]$

47. Metzger M, Flanagin A, Zwarun L. College student Web use, perceptions of information credibility, and verification behavior. Computers \& Education 2003 Nov;41(3):271-290. [doi: 10.1016/S0360-1315(03)00049-6]

48. Haffey F, Brady Richard R W, Maxwell S. Smartphone apps to support hospital prescribing and pharmacology education: a review of current provision. Br J Clin Pharmacol 2014 Jan;77(1):31-38 [FREE Full text] [doi: 10.1111/bcp.12112] [Medline: 23488599]

49. Huckvale K, Morrison C, Ouyang J, Ghaghda A, Car J. The evolution of mobile apps for asthma: an updated systematic assessment of content and tools. BMC Med 2015;13:58 [FREE Full text] [doi: 10.1186/s12916-015-0303-x] [Medline: 25857569]

50. Dillon WA, Prorok JC, Seitz DP. Content and quality of information provided on canadian dementia websites. Can Geriatr J 2013;16(1):6-15 [FREE Full text] [doi: 10.5770/cgj.16.40] [Medline: 23440180]

51. Benigeri M, Pluye P. Shortcomings of health information on the Internet. Health Promot Int 2003 Dec;18(4):381-386 [FREE Full text] [Medline: 14695369]

52. Schneider F, van OL, de VH. Identifying factors for optimal development of health-related websites: a delphi study among experts and potential future users. J Med Internet Res 2012;14(1):e18 [FREE Full text] [doi: 10.2196/jmir.1863] [Medline: 22357411]

53. Wallace LS, Turner LW, Ballard JE, Keenum AJ, Weiss BD. Evaluation of web-based osteoporosis educational materials. J Womens Health (Larchmt) 2005 Dec;14(10):936-945. [doi: 10.1089/jwh.2005.14.936] [Medline: 16372895]

54. Estrada CA, Hryniewicz MM, Higgs VB, Collins C, Byrd JC. Anticoagulant patient information material is written at high readability levels. Stroke 2000 Dec;31(12):2966-2970 [FREE Full text] [Medline: 11108757]

55. Friedman DB, Hoffman-Goetz L, Arocha JF. Health literacy and the World Wide Web: comparing the readability of leading incident cancers on the Internet. Med Inform Internet Med 2006 Mar;31(1):67-87. [doi: 10.1080/14639230600628427] [Medline: 16754369]

56. Friedman DB, Hoffman-Goetz L, Arocha JF. Readability of cancer information on the internet. J Cancer Educ 2004;19(2):117-122. [doi: 10.1207/s15430154jce1902 13] [Medline: 15456669] 


\section{Abbreviations}

F-K: Flesch-Kincaid grade level formula

HONcode: Health on the Net Foundation Code of Conduct

HRWEF: Health-Related Website Evaluation Form

NHMRC: National Health and Medical Research Council

QCSS: Quality Component Scoring System

SAM: Suitability Assessment of Material

SMOG: Simple Measure of Gobbledygook

Edited by G Eysenbach; submitted 06.02.15; peer-reviewed by P Bylaska-Davies, M Chary; comments to author 12.03.15; revised version received 24.04.15; accepted 21.05.15; published 29.09.15

Please cite as:

Taki S, Campbell KJ, Russell CG, Elliott R, Laws R, Denney-Wilson E

Infant Feeding Websites and Apps: A Systematic Assessment of Quality and Content

Interact J Med Res 2015;4(3):e18

URL: $\underline{\text { http: }: / / w w w . i-j m r . o r g / 2015 / 3 / e 18 /}$

doi: 10.2196/ijmr.4323

PMID: 26420339

(CSarah Taki, Karen J Campbell, Catherine G Russell, Rosalind Elliott, Rachel Laws, Elizabeth Denney-Wilson. Originally published in the Interactive Journal of Medical Research (http://www.i-jmr.org/), 29.09.2015. This is an open-access article distributed under the terms of the Creative Commons Attribution License (http://creativecommons.org/licenses/by/2.0/), which permits unrestricted use, distribution, and reproduction in any medium, provided the original work, first published in the Interactive Journal of Medical Research, is properly cited. The complete bibliographic information, a link to the original publication on http://www.i-jmr.org/, as well as this copyright and license information must be included. 